\title{
PM10 elemental composition and acute respiratory health effects in European children (PEACE project)
}

\author{
W. Roemer*, G. Hoek*, B. Brunekreef*, J. Clench-Aas**, B. Forsberg***, J. Pekkanen ${ }^{+}$, A. Schutz ${ }^{++}$
}

PM10 elemental composition and acute respiratory health effects in European children (PEACE project). W. Roemer, G. Hoek, B Brunekreef, J. Clench-Aas, B Forsberg, J. Pekkanen, A. Schutz. C) ERS Journals Ltd 2000.

ABSTRACT: The ability of particles with a 50\% cut-off aerodynamic diameter of 10 $\mu \mathrm{m}$ (PM10) to cause respiratory health effects possibly depends on their composition. This study evaluated whether the soluble elemental concentrations in PM10 were related to acute respiratory health effects. The Pollution Effects on Asthmatic Children in Europe (PEACE) study is a multicentre study of the acute effects of PM10 and other air pollution components on the respiratory health of children with chronic respiratory symptoms in urban and suburban panels.

Children, 1208, divided among 17 panels were followed for $\geq 2$ months. Exposure to air pollution was monitored on a daily basis. Health status was monitored by twice daily peak expiratory flow (PEF) measurements and a symptom diary.

Median concentrations of iron ranged $105-1,110 \mathrm{ng} \cdot \mathrm{m}^{-3}$ in the urban and 32-517 $\mathrm{ng} \cdot \mathrm{m}^{-3}$ in the suburban locations. The daily concentrations of most elements were not associated with daily variation in PEF, prevalence of respiratory symptoms or bronchodilator use. Silicon and iron concentrations tended to be negatively associated with PEF, and positively associated with the prevalence of phlegm. In two pollutant models, PM10 effect-estimates on phlegm prevalence were reduced and lost significance, whereas the effect-estimates of iron or silicon remained essentially unchanged. The effects of silicon and iron could not be separated.

In conclusion, this study provides only weak support for the hypothesis that daily fluctuations in soluble elemental concentrations in ambient particulate matter are responsible for acute health effects.

Eur Respir J 2000; 15: 553-559. *Environmental and Occupational Health
Group, Agricultural University Wagenin-
gen, the Netherlands. **Norwegian In-
stitute for Air Research, Kjeller, Norway.
***Dept of Public Health and Clinical
Medicine, Umeå University, Sweden.
${ }^{+}$National Public Health Institute, Kuo-
pio, Finland. ${ }^{++}$Dept of Occupational and
Environmental Medicine, University Hos-
pital, Lund, Sweden.

Correspondence: W. Roemer, Environmental and Occupational Health Group, Agricultural University Wageningen, P.O. Box 238, 6700 AE Wageningen, The Netherlands. Fax: 31317485278

Keywords: Children, elemental composition, epidemiology, particulate matter, respiratory symptoms

Received: February 251999

Accepted after revision November 251999

The Pollution Effects on Asthmatic Children in Europe (PEACE) study was funded within the framework of the Commission of the European Communities Environment Programme, contracts EV5V-CT920220, CIPD-CT-92-5052, ERBCIPD-CT93-0046 and ENV4-CT95-0168. The Finnish, Norwegian and two Swedish centres were funded by grants from their respective governments.
Several studies have shown acute effects of particles with a 50\% cut-off aerodynamic diameter of $10 \mu \mathrm{m}$ (PM10) on morbidity and mortality [1]. The mechanism through which PM10 is related to respiratory health is unclear. One hypothesis for explaining the acute respiratory ef-fects associated with PM10 is that certain elements such as transition metals in the particles cause damage via the generation of free radicals and that PM10 mass concentrations serve as a proxy for these elements [2]. Iron, particularly, has been mentioned in this context as it is known from earlier studies that iron is able to generate hydroxyl radicals through the Fenton reaction [3, 4]. PM10 sampled in Edinburgh, UK was able to generate hydroxyl radicals in vitro, possibly through involvement of iron [5]. Other transition metals (titanium, vanadium, chromium, manganese, cobalt, nickel, copper and zinc) from a variety of urban or combustion source samples were also related to lung injury and radical activation in animal experiments [5-9].

Epidemiological studies on the acute effects of elemental concentrations in PM10 on respiratory health are scarce. One study in the Netherlands showed that airborne iron was associated with exacerbation of respiratory symptoms and with increased maintenance medication use, independently of PM10 [10]. A study on daily mortality in Rotterdam, the Netherlands showed that the total iron content of total suspended practicalities (TSP) was less consistently associated with mortality than TSP mass [11]. A limitation of these studies is that the total iron content was used as the exposure measure. The conditions in the human airways and macrophages are such that probably only soluble elements are released from inhaled particles.

This study evaluated whether soluble elemental concentrations in PM10 are related to acute effects on respiratory health, using data from the Pollution Effects on Asthmatic Children in Europe (PEACE) study.

\section{Material and methods}

The Pollution Effects on Asthmatic Children in Europe study

The PEACE study is a collaboration of 14 European centres: Amsterdam (the Netherlands), Kuopio (Finland), 
Oslo (Norway), Berlin and Hettstedt (Germany), Pisa (Italy), Athens (Greece), Cracow and Katowice (Poland), Prague and Teplice (Czech Republic), Budapest (Hungary), and Umeå and Malmö (Sweden). All centres used the same protocol for data collection and analysis. The design, methods and results of the individual panels [12] as well as the combined effect-estimates for PM10 and other components are reported elsewhere [13]. Each centre selected two panels, one in an urban area and one in a suburban or rural area (hereafter referred to as suburban panel). The suburban panel was selected from a community which had no major traffic emissions or large industrial sources, and was of sufficient size for the selection of enough subjects and close to the site of an existing air pollution measurement network.

Children aged 6-12 yrs with chronic respiratory symptoms were selected by means of a parent-completed screening questionnaire. The criteria for selection were: reporting of recent wheeze (apart from colds), recent attacks of shortness of breath with wheezing, recent dry cough (apart from colds), and/or doctor-diagnosed asthma, ever in life.

Peak expiratory flow (PEF) was measured each day in the morning and in the evening for $\geq 2$ months in the winter of 1993/1994. For analysis, the highest of three readings was used. All centres used the mini Wright Peak Flow meter (Clement Clarke International, Harlow, UK). A parent completed a daily diary for the child, recording the presence and severity of respiratory symptoms and use of medication for respiratory symptoms. The symptoms in the diary were cough, phlegm, runny/stuffed nose, woken up with breathing problems, shortness of breath, wheeze, attack(s) of shortness of breath with wheeze, fever, eye irritation, and sore throat. To avoid large changes in the composition of the reporting group of children on separate days, children were included in the analysis if they had valid PEF measurements and respiratory symptom data on $>60 \%$ of days.

Concurrent air pollution measurements were performed in both the urban and suburban locations. Daily 24-h measurements of PM10, black smoke (BS), sulphur dioxide and nitrogen dioxide were made at sites not influenced by nearby sources, so-called background sites. More information about the measurement methods and combined effectestimates of PM10, BS, $\mathrm{SO}_{2}$ and $\mathrm{NO}_{2}$ on respiratory health for all panels are given elsewhere [12-14].

\section{Filter analysis}

The filters were transferred, by use of plastic tweezers, into $15-\mathrm{mL}$ polypropylene tubes with screw caps. In an attempt to differentiate between fractions of elements of high and low bioavailability, a two-step extraction was conducted, based on the procedure described by JANSSEN $e t$ $a l$. [15]. In the first step, the PM10 filters were extracted with $10 \mathrm{~mL}$ of a dilute acid solution (0.05 M HF, 0.01 M $\mathrm{HNO}_{3}$ ). The tubes were agitated end-over-end for $4 \mathrm{~h}$, centrifuged and $8 \mathrm{~mL}$ of the extract transferred to another polypropylene tube for analysis. In the second extraction step, 100 times higher concentrations of the acids were used. Only the results of the dilute acid extraction have been used to study associations with respiratory health. The extracts were analysed by use of low-resolution inductively coupled plasma mass spectometry (ICP-MS;
VG PQ2+, Fisons Elemental, Winsford, UK). The instrument was operated in dual mode (analogue and pulse counting), and the samples were introduced in segmented flow mode by use of an autosampler (Gilson 222; Gilson, Villiers, France). The concentrations of the elements aluminium, arsenic, boron, barium, bismuth, calcium, cadmium, cerium, cobalt, chromium, caesium, copper, francium, lanthanum, lithium, magnesium, manganese, molybdenum, sodium, nickel, lead, rubidium, silicon, tin, strontium, titanium, vanadium, tungsten, zinc and zirconium were determined.

The instrument was calibrated by use of multi-element standard solutions made up by mixing certified single standard solutions with the acid solution in proportions expected to reflect the elemental composition of the samples.

The filter extraction and analysis were carried out in one laboratory (Lund, Sweden). Instrument performance was checked by including a separate commercial certified reference multi-element standard solution, diluted with the extraction solutions, once every 20 samples in all sample series. The coefficients of variation calculated from all of the available reference samples were for iron $15.8 \%$, nickel $8.6 \%$, zinc $8.3 \%$, vanadium $9.4 \%$, sodium $8.4 \%$ and lead $8.8 \%$. For silicon, which was not included in the certified reference solution, the coefficient of variation was calculated from the method calibration solution and was $12.6 \%$.

The results of field blanks (filters left unexposed in samplers and handled as exposed filters) were subtracted from the results of exposed filters. Because not all centres used the same filter and because the mean field blank values differed between centres using the same type of filter, filter- and centre-specific mean field blank values were calculated. If no field blanks were provided by a centre, the mean field blank values of the other centres using the same type of filter were used.

In Finland, $\sim 50 \%$ of the filters from the urban site were no longer available for analysis by ICP-MS. The results from an additional urban site were used to estimate the missing values. PM10 concentrations from this additional site were highly correlated with PM10 concentrations from the main urban site [16]. A regression model was calculated using the nonmissing data from the urban site as the dependent variable and the data from the additional site as the independent variable. The resulting model was used to predict missing observations. This method was not used for nickel, lead and silicon as for those elements the correlation between the nonmissing observations in the urban and additional site was considered too low $\left(\mathrm{r}^{2}\right.$ $<0.50)$ to give reliable estimates.

\section{Statistical methods}

All panels were analysed separately, using the same methods used previously for PM10 and other components $[12,14]$. Individual daily PEF readings were transformed into a daily population variable representing the population mean for each day of the individual deviations from the child-specific mean PEF $[12,17,18]$. This was done separately for morning and evening PEF ( $\triangle \mathrm{PEFam}$ and $\triangle \mathrm{PEF} p \mathrm{pm}$ ). The association between daily elemental concentrations and daily $\triangle \mathrm{PEFam}$ and $\triangle \mathrm{PEFpm}$ was calculated by means of linear regression weighted for the number of reporting children on each day. Correction for 
auto-correlation in the residuals was made using a firstorder autoregressive model.

The symptoms in the diaries were recoded as 0 (no symptom) and 1 (slight, moderate or severe symptom) and their daily prevalence was calculated. Daily prevalence was defined as the fraction of children providing valid diary data for that symptom on that day for whom the presence of a respiratory symptom/medication use was reported. The association between symptom prevalence and air pollution was evaluated by means of logistic regression analysis, weighted for the number of reporting children on each day and correcting for first-order autocorrelation in the residuals. The respiratory symptoms cough and phlegm and the symptom combinations upper respiratory symptoms (runny/stuffed nose and sore throat) and lower respiratory symptoms (shortness of breath, wheeze and asthma attacks) were analysed. The prevalence of bronchodilator use (such as salbutamol, albuterol, fenoterol and terbutaline) was also analysed.

The explanatory variables were 24 -h mean elemental concentrations, entered separately into the regression models. To reduce the possibility that results would be influenced by chance findings, a limited number of elements were chosen a priori from those available to be included in the time series analysis. The other elements were not analyzed. Nickel, zinc, vanadium and iron were included because of the capability of these transition metals to generate radicals in toxicological studies [3-6, 8, 9]. Additional reasons for the inclusion of vanadium and iron were that vanadium can serve as a tracer for oil combustion and iron has been shown to be related to acute effects on respiratory health [10]. Silicon, sodium and lead were included as possible tracers for soil dust, sea spray, and leaded car fuel, respectively. The current day (lag0), previous day (lag1), day before the previous day (lag2) and the mean average of lag0-6 days (7-day mean) concentrations were analysed separately. Minimum temperature, a dummy variable indicating normal school days versus holidays/ weekends and time trend were included as potential confounders. Time trend was included as a linear and square root term for PEF analysis and as a third-order polynomial in the prevalence analysis. Influential observations were identified by calculating Cook's distance [19]. Observations with a Cook's D of $>0.8$ were excluded from the analysis in order to avoid one or a few observations determining the association for the whole set of observations. The regression slopes of the air pollution components from the linear and logistic regression models for each panel were used to calculate combined effectestimates.

A combined fixed effect-estimate was calculated as the weighted mean of the panel-specific slopes with the weights inversely proportional to the panel-specific variance. The SEM of the combined slope was calculated as the inverse of the square root of the sum of the weights [20]. The heterogeneity of panel-specific slopes was evaluated using a Chi-squared test for homogeneity [20]. In cases of homogeneity, the combined slope calculated as a fixed effect was considered an appropriate estimate. A conservative cut-off point of $\mathrm{p}<0.25$ was chosen to determine heterogeneity. In cases of heterogeneity $(p<0.25)$, combined effect-estimates using random effect-estimation were calculated using the noniterative method with unequal weights [20].
In order to make comparison with earlier studies possible, in this paper only the results of the health endpoints which were related to air pollution in earlier panel studies in children are presented [17, 18, 21]. In addition, endpoints which show some pattern in association with elemental composition in the current analysis are also presented.

\section{Results}

For 17 of the 28 panels of the PEACE study, enough filters were available for ICP-MS analysis to perform time series analysis with the elemental concentrations as independent variable. Table 1 shows the characteristics of the included locations and panels. PM10 levels were lowest in Northern Europe and higher in Eastern and Southern Europe. More details on PM10 levels during the study period can be found elsewhere [14]. In table 2, some descriptive statistics of the elemental concentrations are presented. A large range of elemental concentrations can be seen, again with generally lower concentrations in Northern Europe and higher concentrations in Eastern and Southern Europe. The median and maximum concentrations tend to be higher in the urban than in the suburban locations. Iron, zinc, silicon and lead concentration, in particular, show a large contrast between urban and suburban locations in most centres, but large differences can also be found for the other elements in some centres.

Spearman correlations between elemental concentrations and PM10 mass concentrations were positive in all locations for most elements. The median correlations of the locations were 0.70 (iron), 0.49 (nickel), 0.71 (zinc), 0.60 (vanadium), 0.76 (lead) and 0.39 (silicon). Only the correlation between sodium and PM10 was negative in most locations, with a median correlation of -0.08 . A more detailed discussion of the elemental concentrations is not within the scope of this paper and will be published elsewhere.

Table 1. - Characteristics of panels

\begin{tabular}{|c|c|c|c|c|c|c|c|}
\hline & Panel & $\begin{array}{l}\mathrm{PM} 10 \\
\mu \mathrm{g} \cdot \mathrm{m}^{-3}\end{array}$ & $\underset{\mu \mathrm{g} \cdot \mathrm{m}}{\mathrm{SO}_{2-3}}$ & $\begin{array}{r}\mathrm{NO}_{2} \\
\mu \mathrm{g} \cdot \mathrm{m}^{-3}\end{array}$ & $\begin{array}{l}\text { Sub- } \\
\text { jects }\end{array}$ & $\begin{array}{l}\text { Cough } \\
\%^{*}\end{array}$ & $\underset{\%^{+}}{\text {Bron }}$ \\
\hline Umeå, & Urban & 13.4 & 2.7 & 25.0 & 75 & 15 & 10 \\
\hline Sweden & Suburban & 11.5 & 4.0 & 15.3 & 72 & 17 & 22 \\
\hline Kuopio, & Urban & 17.7 & 6.0 & 28.4 & 85 & 54 & 3 \\
\hline Finland & Suburban & 13.0 & - & 13.7 & 84 & 58 & 7 \\
\hline Oslo, & Urban & 19.3 & 12.4 & 49.3 & 56 & 36 & 3 \\
\hline Norway & Suburban & 11.2 & 3.4 & 15.3 & 68 & 55 & 10 \\
\hline $\begin{array}{l}\text { Amsterdam, } \\
\text { the Nether- }\end{array}$ & Urban & 45.3 & 13.2 & 46.4 & 55 & 38 & 4 \\
\hline lands & Suburban & 44.4 & 8.5 & 26.5 & 71 & 44 & 3 \\
\hline Berlin, & Urban & 52.3 & 42.3 & 38.3 & 50 & 4 & 17 \\
\hline Germany & Suburban & 43.0 & 26.1 & 21.2 & 66 & 3 & 8 \\
\hline Hettstedt, & Urban & 40.3 & 83.3 & 26.5 & 75 & 21 & 2 \\
\hline Germany & Suburban & 32.9 & 64.9 & 26.1 & 63 & 10 & 5 \\
\hline Katowice, & Urban & 68.7 & 55.7 & 68.7 & 72 & 35 & 1 \\
\hline Poland & Suburban & 73.8 & 56.0 & 69.5 & 73 & 15 & 3 \\
\hline Budapest, & & & & & & & \\
\hline Hungary & Urban & 60.9 & 49.7 & 35.3 & 76 & 45 & 2 \\
\hline Athens, & Urban & 98.8 & 72.4 & 74.9 & 87 & 53 & 4 \\
\hline Greece & Suburban & 50.0 & - & 19.7 & 80 & 31 & 7 \\
\hline
\end{tabular}

Bron: bronchodilator use; *: percentage of children in panel selected only on basis of question on nightly coughing; ${ }^{+}$: mean prevalence of bronchodilator use in panel during study period. 
Table 2. - 24-h mean soluble elemental concentrations

\begin{tabular}{|c|c|c|c|c|c|c|c|c|c|}
\hline & \multirow{2}{*}{ Panel } & \multirow{2}{*}{$\begin{array}{c}\text { Obs } \\
\mathrm{n}\end{array}$} & \multicolumn{7}{|c|}{ Mean soluble elemental concentration $\mathrm{ng} \cdot \mathrm{m}^{-3}$} \\
\hline & & & Iron & Nickel & Zinc & Vanadium & Sodium & Lead & Silicon \\
\hline \multirow[t]{2}{*}{ Umeå, Sweden } & ban & 6 & 124( & $0.8(5.1)$ & $15.4(60$ & (13.9) & $311(13$ & $7.0(34.9)$ & 142( \\
\hline & Suburban & 64 & $65(230)$ & $1.0(6.2)$ & $14.6(87.6)$ & $2.0(16.8)$ & $253(1117)$ & $5.0(54.5)$ & $70(1668)$ \\
\hline \multirow[t]{2}{*}{ Kuopio, Finland } & Urban & 57 & $124(1880)$ & $1.0(5.3)^{*}$ & $18.9(56.0)$ & $3.8(17.7)$ & $278(787)$ & $5.1(18.1)^{*}$ & $104(4873)^{*}$ \\
\hline & Suburban & 57 & $32(732)$ & $1.3(4.7)$ & $13.3(75.7)$ & $2.2(16.3)$ & $253(768)$ & $4.5(14.0)$ & $0(2538)$ \\
\hline \multirow[t]{2}{*}{ Oslo, Norway } & Urban & 67 & $105(905)$ & $0.2(1.7)$ & $6.9(55.8)$ & $2.0(9.2)$ & $236(1282)$ & $22.9(202.5)$ & $89(4015)$ \\
\hline & Suburban & 68 & 49 (389) & $0.0(0.6)$ & $3.1(23.0)$ & $1.3(8.4)$ & $157(1034)$ & $10.5(53.3)$ & $30(1396)$ \\
\hline \multirow{2}{*}{$\begin{array}{l}\text { Amsterdam, } \\
\text { the Netherlands }\end{array}$} & Urban & 66 & $187(1200)$ & $2.8(22.8)$ & $54.1(666.2)$ & $6.6(37.4)$ & $926(7461)$ & $20.8(177.2)$ & $126(3324)$ \\
\hline & Suburban & 58 & $70(3776)$ & $0.0(1678.8)$ & $15.9(117.8)$ & $3.3(20.8)$ & $283(4576)$ & $14.6(93.0)$ & $71(8539)$ \\
\hline \multirow[t]{2}{*}{ Berlin, Germany } & Urban & 44 & $536(1180)$ & $2.9(8.5)$ & $91.5(473.5)$ & $5.7(31.4)$ & $482(1925)$ & $64.8(228.0)$ & $380(1877)$ \\
\hline & Suburban & 47 & $283(1290)$ & $2.4(24.9)$ & $86.6(695.3)$ & $4.9(31.6)$ & $441(1847)$ & $37.7(209.1)$ & $88(2934)$ \\
\hline \multirow[t]{2}{*}{ Hettstedt, Germany } & Urban & 31 & $146(933)$ & $1.0(6.6)$ & $309.1(2049.1)$ & $2.2(13.7)$ & 445 (1429) & $116.4(562.3)$ & $162(1515)$ \\
\hline & Suburban & 30 & $133(501)$ & $1.1(6.2)$ & $60.9(171.8)$ & $1.9(13.9)$ & $401(1573)$ & $28.3(258.7)$ & $11(980)$ \\
\hline \multirow[t]{2}{*}{ Katowice, Poland } & Urban & 28 & $881(2510)$ & $4.0(8.8)$ & $121.3(730.8)$ & $4.2(8.9)$ & $573(1854)$ & $115.8(346.7)$ & $2048(5105)$ \\
\hline & Suburban & 29 & $517(1210)$ & $2.2(38.2)$ & $69.0(417.1)$ & $2.8(9.4)$ & $536(1398)$ & $82.1(181.2)$ & $1320(2814)$ \\
\hline Budapest, Hungary & Urban & 39 & $363(1060)$ & $4.2(16.5)$ & $71.9(314.0)$ & $7.4(48.6)$ & $229(693)$ & $49.7(215.6)$ & $900(2406)$ \\
\hline \multirow[t]{2}{*}{ Athens, Greece } & Urban & 56 & $1110(2830)$ & $5.3(46.1)$ & $92.8(477.2)$ & $8.6(24.0)$ & $695(3974)$ & $377.1(769.8)$ & $936(3474)$ \\
\hline & Suburban & 55 & $147(568)$ & $2.4(19.0)$ & $22.7(104.2)$ & $5.3(18.8)$ & $742(3441)$ & $45.5(157.8)$ & $303(1956)$ \\
\hline
\end{tabular}

Data are presented as median (maximum). *: no estimate of missing values possible $(\mathrm{n}=28)$. Obs: observations.

The effect-estimates of the elemental concentrations on $\triangle \mathrm{PEF}$ am and $\triangle \mathrm{PEFpm}$ do not show a significant effect (table 3). The coefficients of iron and silicon are predominantly negative but do not reach significance. The effect-estimates of PM10 on $\triangle \mathrm{PEF}$ am and $\triangle \mathrm{PEFpm}$ for the included 17 panels are also presented in table 3 and show a significant negative association only for PM10 lag1 on $\triangle$ PEFpm. After specification of a two-pollutant model with the concentrations of PM10 and iron or PM10 and silicon simultaneously included, the effect-estimates of neither PM10 nor iron or silicon showed clear associations with PEF (data not shown).

The effect-estimates of elemental concentrations on prevalence of upper respiratory symptoms or cough did not show a clear association (data not shown). Most elements also did not show a consistent positive association with prevalence of phlegm, lower respiratory symptoms and bronchodilator use (table 4). Only iron and silicon have consistently positive odds ratios (ORs) with phlegm, most of them (borderline) significant. To illustrate the consistency of the ORs across centres, the individual panel and the combined effect-estimates for silicon lag1 are shown in figure 1. Most panel-specific ORs were $>1$, several of them significantly. There is no effect-estimate of Kuopio urban available as the regression model did not converge, probably due to the low number of observations. The combined effect-estimate of PM10 lag1 showed a positive significant association with phlegm as well, but the other representations were $\sim 1$ (table 4 ). When specifying a two-pollutant model with the concentrations of PM10 and iron or PM10 and silicon simultaneously included, the PM10 effect-estimates on phlegm prevalence were reduced and lost significance (data not shown). For example, for lag1 of PM10 and iron simultaneously, the estimates became 1.07 (95\% confidence interval (CI) 0.94-1.22) for PM10 and 1.08 (95\% CI 0.94-1.25) for iron. For PM10 and silicon these became 1.02 (95\% CI $0.86-1.20)$ and 1.10 (95\% CI 1.02-1.18) respectively. The effect-estimates of the other lags of iron and silicon essentially did not change and, in spite of increased CIs, the silicon effect-estimates remained significant.
Restriction of the data to the eight panels with the highest interquartile ranges of elemental concentration did not change the pattern for any combination of exposure and health outcome variable. Stratification on urban/suburban locations showed that in the suburban locations, the associations tended to be more in the expected direction than in the urban locations. Stratification on geographical location, defined as North (Umeå, Oslo and Kuopio), West (Amsterdam and Berlin), East (Hettstedt, Katowice and Budapest) and South (Athens), showed that the associations between silicon and phlegm tended to be stronger in the West and North than in the East or South. For example, the ORs (95\% CIs) for silicon lag1 were: North 1.11 (1.041.18), West 1.25 (1.11-1.40), East 1.01 (0.94-1.09), and South $1.04(0.95-1.15)$.

\section{Discussion}

The elemental concentrations measured showed a wide range across 17 European locations, with generally higher concentrations in the urban locations. Also, within the locations, the concentrations showed a large range. Concentrations of most elements were not associated with $\triangle \mathrm{PEF}$ am or $\triangle \mathrm{PEFpm}$ or with daily prevalence of respiratory symptoms and bronchodilator use. Iron and, especially, silicon were positively associated with the prevalence of phlegm and tended to have negative associations with PEF.

The elemental concentrations showed a greater difference between urban and suburban locations than did PM10 mass concentrations. Also, the difference between geographical locations was greater for elemental concentrations than for PM10 mass concentration. PM10 mass concentrations differed between urban and suburban locations by on average $22 \%$ [14]. Elemental concentrations for elements such as silicon, iron, zinc and lead differed more than two-fold in several locations. An explanation for this difference might be that not all elements which contribute to PM10 mass concentration have been identified, such as sulphur (from sulphates), nitrogen (from nitrates) and carbon. The fact that silicon and iron concentrations were 
Table 3. - Combined effect-estimates with 95\% confidence intervals $(95 \% \mathrm{Cl})$ of air pollution on peak expiratory flow (PEF)

\begin{tabular}{|c|c|c|c|c|c|}
\hline & \multirow{2}{*}{$\begin{array}{l}\text { Esti- } \\
\text { mate } \\
\text { n }\end{array}$} & \multicolumn{2}{|c|}{$\triangle \mathrm{PEFam} *$} & \multicolumn{2}{|c|}{$\triangle \mathrm{PEFpm} *$} \\
\hline & & Mean & $95 \% \mathrm{CI}$ & Mean & $95 \%$ CI \\
\hline \multicolumn{6}{|l|}{ Iron } \\
\hline Lag0 & 17 & -0.2 & $-1.1-0.7^{\#}$ & 0.1 & $-0.8-1.0^{\#}$ \\
\hline Lag1 & 17 & -0.1 & $-0.8-0.6^{\S}$ & -0.3 & $-1.0-0.4^{\S}$ \\
\hline Lag2 & 17 & -0.6 & $-1.3-0.1^{\S}$ & -0.4 & $-1.1-0.3^{\S}$ \\
\hline 7-day mean ${ }^{+}$ & 15 & 1.1 & $-1.5-3.7^{\#}$ & -0.2 & $-3.0-2.6^{\#}$ \\
\hline \multicolumn{6}{|l|}{ Nickel } \\
\hline Lag0 & 17 & -0.3 & $-1.1-0.5^{\S}$ & 0.2 & $-0.5-0.9^{\S}$ \\
\hline Lag1 & 17 & -0.6 & $-1.5-0.3^{\S}$ & -0.2 & $-0.9-0.5^{\S}$ \\
\hline Lag2 & 17 & -0.2 & $-1.5-1.2^{\#}$ & -0.8 & $-2.0-0.3^{\#}$ \\
\hline 7-day mean ${ }^{+}$ & 15 & 0.8 & $-1.8-3.4^{\#}$ & 0.8 & $-2.3-4.0^{\#}$ \\
\hline \multicolumn{6}{|l|}{ Zinc } \\
\hline Lag0 & 17 & -0.1 & $-0.8-0.6^{\S}$ & -0.2 & $-0.8-0.4^{\S}$ \\
\hline Lag1 & 17 & -0.2 & $-0.8-0.4^{\S}$ & 0.0 & $1.1-1.2^{\#}$ \\
\hline Lag2 & 17 & -0.2 & $-1.6-1.1^{\#}$ & -0.5 & $-1.6-0.7^{\#}$ \\
\hline 7-day mean ${ }^{+}$ & 15 & 1.3 & $-4.1-6.7^{\#}$ & 0.7 & $-3.9-5.3^{\#}$ \\
\hline \multicolumn{6}{|l|}{ Vanadium } \\
\hline Lag0 & 17 & 0.0 & $-1.3-1.3^{\#}$ & 0.2 & $-0.7-1.2^{\S}$ \\
\hline Lag1 & 17 & 0.3 & $-1.1-1.6^{\#}$ & -0.1 & $-1.3-1.1^{\#}$ \\
\hline Lag2 & 17 & 0.2 & $-1.1-1.5^{\#}$ & -0.1 & $-1.7-1.5^{\#}$ \\
\hline 7-day mean ${ }^{+}$ & 15 & 1.3 & $-2.3-4.8^{\#}$ & 0.5 & $-3.6-4.7^{\#}$ \\
\hline \multicolumn{6}{|l|}{ Sodium } \\
\hline Lag0 & 17 & -0.1 & $-0.7-0.5^{\#}$ & -0.1 & $-0.5-0.3^{\S}$ \\
\hline Lag1 & 17 & 0.0 & $-0.4-0.4^{\S}$ & -0.2 & $-0.8-0.4^{\#}$ \\
\hline Lag2 & 17 & 0.1 & $-0.3-0.5^{\S}$ & 0.0 & $-0.4-0.4^{\S}$ \\
\hline 7-day mean ${ }^{+}$ & 15 & -1.4 & $-3.5-0.7^{\#}$ & -0.6 & $-2.4-1.2^{\#}$ \\
\hline \multicolumn{6}{|l|}{ Lead } \\
\hline Lag0 & 17 & 0.1 & $-0.2-0.5^{\S}$ & 0.1 & $-0.4-0.7^{\#}$ \\
\hline Lag1 & 17 & 0.0 & $-0.6-0.6^{\#}$ & -0.4 & $-0.7-0.0^{\S}$ \\
\hline Lag2 & 17 & 0.3 & $-0.4-1.0^{\#}$ & -0.1 & $-0.7-0.4^{\#}$ \\
\hline 7-day mean ${ }^{+}$ & 15 & 1.4 & $-0.7-3.5^{\#}$ & 0.2 & $-2.0-2.4^{\#}$ \\
\hline \multicolumn{6}{|l|}{ Silicon } \\
\hline Lag0 & 17 & -0.6 & $-1.2-0.0^{\#}$ & -0.2 & $-0.8-0.4^{\#}$ \\
\hline Lag1 & 17 & 0.0 & $-0.4-0.4^{\S}$ & -0.4 & $-0.9-0.1^{\#}$ \\
\hline Lag2 & 17 & -0.3 & $-0.8-0.2^{\#}$ & -0.4 & $-0.8-0.0^{\S}$ \\
\hline 7-day mean ${ }^{+}$ & 15 & -0.1 & $-0.9-0.7^{\S}$ & -0.7 & $-2.0-0.6^{\#}$ \\
\hline \multicolumn{6}{|l|}{ PM10 } \\
\hline Lag0 & 17 & 0.5 & $-0.2-1.2^{\S}$ & 0.1 & $-0.6-0.8^{\S}$ \\
\hline Lag1 & 17 & -0.1 & $-1.0-0.8^{\S}$ & -1.1 & $-1.8--0.4^{\S}$ \\
\hline Lag2 & 17 & 0.3 & $-0.5-1.1^{\S}$ & -0.8 & $-1.6-0.0^{\S}$ \\
\hline 7-day mean ${ }^{+}$ & 17 & -0.8 & $-3.0-1.4^{\#}$ & -1.6 & $-4.0-0.8^{\#}$ \\
\hline
\end{tabular}

*: $\mathrm{L} \cdot \mathrm{min}^{-1}$ per $1,000 \mathrm{ng} \cdot \mathrm{m}^{-3}$ (iron, sodium, silicon), $300 \mathrm{ng} \cdot \mathrm{m}^{-3}$ zinc), $100 \mathrm{ng} \cdot \mathrm{m}-3$ (lead), $20 \mathrm{ng} \cdot \mathrm{m}^{-3}$ (vanadium), $10 \mathrm{ng} \cdot \mathrm{m}^{-3}$ (nickel), and $100 \mu \mathrm{g} \cdot \mathrm{m}^{-3} ;{ }^{+}$: panel-specific; ${ }^{+}:$Hettstedt urban and suburban filters were only available once every 3 days and so reliable 7-day means could not be calculated; ${ }^{\text {\$ }}$ : fixed effects model; \#: random effects model. $\triangle \mathrm{PEFam}$ : population mean deviation from mean morning PEF; $\triangle \mathrm{PEFpm}$ : population mean deviation from mean evening PEF; lag0: current day; lag1: previous day; lag2: day before previous day; 7-day mean: mean of lag0-6 days.

higher in urban locations might be caused by a higher traffic intensity, which causes resuspension of road dust [15]. Industrial sources may also contribute to the iron level. The higher lead concentrations can be caused by a higher traffic intensity, but also by industrial emissions. The differences in zinc concentrations can be caused by resuspended road dust, smelting operations, coal and wood combustion, and wearing down of vehicle tyres [22].
A large number of combinations of exposure variables and health end points have been evaluated in this study. Most associations were insignificant, some associations were found for silicon and iron (with phlegm and PEF). It is not thought that these associations are just chance findings. First, for all four evaluated lags of silicon and iron, a positive association was found with phlegm. Five of the eight associations were statistically significant and two of them borderline significant. Secondly, from figure 1, it is clear that most individual panels have ORs of $>1$, some significant. These individual panels should be regarded as separate studies, which reduces the possibility that the overall findings are caused by chance. Finally, although not statistically significant, iron and silicon also tended to be associated with PEF. Earlier studies have shown mixed results regarding associations between phlegm prevalence and PM10 levels. In a panel of symptomatic children in the Netherlands, phlegm prevalence was not related to PM10 [23], whereas, in a panel of asthmatic children in the Czech Republic, there was a positive association between phlegm prevalence and PM10 levels [24]. The results of this study do not support strongly the hypothesis that transition metals are responsible for the association between PM10 and respiratory health. Firstly, associations with respiratory health were only found for iron and silicon and not for other transition metals. Secondly, iron was not more consistently associated with respiratory health than PM10 mass concentration (PEF) and silicon (PEF and phlegm). Thirdly, associations were found only for phlegm and, less consistently, PEF. Other studies have documented the strongest associations with PM10 for lower respiratory symptoms and bronchodilator use [1, $17,18,23]$. With the end points used in these previous studies, no association was observed. A limitation of the present study is that no consistent association between particle mass (PM10 mass concentration) and respiratory health was observed. Confounding by respiratory infection may have been a cause of this lack of association in the PEACE study as a whole, and an extensive discussion of possible explanations is contained in an earlier paper [13]. Another possibility is that PM10 mass concentration was too crude an exposure indicator and that better indicators of exposure such as the concentration of soluble transition metals would reveal an association with respiratory health. This hypothesis was not supported. It remains useful to further evaluate the hypothesis of soluble transition metals in studies showing clearer effects of PM10 mass concentration. In this study, silicon and iron showed a larger coefficient of variation in measurement precision than did the other elements. This leads to more exposure misclassification. As the exposure misclassification is probably random, this biases the effect-estimates of iron and silicon more towards no association than the other elements. A panel of adult asthma patients in the Netherlands showed an association between elemental concentrations and respiratory health [10]. In that study, iron concentrations were related to PEF, the prevalence of medication use and the prevalence of moderate or severe respiratory symptoms (shortness of breath and attacks of shortness of breath with wheeze but not phlegm). The maximum daily iron concentrations were generally higher than those found in the PEACE panels, but this might be because the total iron concentration was determined and not the soluble fraction as in the PEACE study. Further, 
Table 4. - Combined odds ratios (ORs) and 95\% confidence intervals (95\% Cls) for increase in air pollution on prevalence of phlegm, lower respiratory symptoms and bronchodilator use

\begin{tabular}{|c|c|c|c|c|c|c|c|c|c|}
\hline & \multicolumn{3}{|c|}{ Phlegm* } & \multicolumn{3}{|c|}{ Lower respiratory symptoms* } & \multicolumn{3}{|c|}{ Bronchodilator use* } \\
\hline & $\underset{n}{\text { Estimate }}$ & OR & $95 \% \mathrm{CI}$ & $\underset{n}{\text { Estimate }}$ & OR & $95 \% \mathrm{CI}$ & $\underset{n}{\text { Estimate }}$ & OR & $95 \% \mathrm{CI}$ \\
\hline \multicolumn{10}{|l|}{ Iron } \\
\hline $\operatorname{Lag} 0$ & 17 & 1.05 & $0.93-1.19^{\#}$ & 17 & 1.09 & $0.95-1.24^{\#}$ & 16 & 1.08 & $0.99-1.17^{\S}$ \\
\hline Lag1 & 17 & 1.15 & $1.02-1.30^{\#}$ & 17 & 1.04 & $0.88-1.23^{\#}$ & 16 & 0.98 & $0.90-1.07^{\S}$ \\
\hline Lag2 & 17 & 1.13 & $1.00-1.28^{\#}$ & 17 & 0.96 & $0.80-1.15^{\#}$ & 16 & 1.05 & $0.96-1.14^{\S}$ \\
\hline 7-day mean ${ }^{+}$ & 15 & 1.25 & $0.98-1.59^{\#}$ & 15 & 0.96 & $0.66-1.40^{\#}$ & 14 & 0.90 & $0.66-1.23^{\#}$ \\
\hline \multicolumn{10}{|l|}{ Nickel } \\
\hline Lag0 & 17 & 1.00 & $0.89-1.12^{\S}$ & 17 & 0.93 & $0.84-1.03^{\S}$ & 16 & 0.99 & $0.89-1.11^{\S}$ \\
\hline Lag1 & 17 & 0.96 & $0.83-1.12^{\#}$ & 17 & 0.93 & $0.84-1.03^{\S}$ & 16 & 0.98 & $0.84-1.14^{\#}$ \\
\hline Lag2 & 17 & 0.88 & $0.73-1.06^{\#}$ & 17 & 0.88 & $0.68-1.15^{\#}$ & 16 & 1.06 & $0.95-1.17^{\S}$ \\
\hline 7-day mean ${ }^{+}$ & 15 & 1.04 & $0.84-1.30^{\#}$ & 15 & 0.57 & $0.35-0.92^{\#}$ & 14 & 1.01 & $0.78-1.32^{\#}$ \\
\hline \multicolumn{10}{|l|}{ Zinc } \\
\hline Lag0 & 17 & 0.97 & $0.91-1.04^{\S}$ & 17 & 0.95 & $0.85-1.07^{\S}$ & 16 & 0.95 & $0.88-1.03^{\S}$ \\
\hline Lag1 & 17 & 0.97 & $0.87-1.08^{\#}$ & 17 & 0.95 & $0.80-1.12^{\#}$ & 16 & 1.04 & $0.92-1.17^{\#}$ \\
\hline Lag2 & 17 & 0.99 & $0.88-1.12^{\#}$ & 17 & 0.87 & $0.74-1.01^{\#}$ & 16 & 1.03 & $0.91-1.17^{\#}$ \\
\hline 7-day mean ${ }^{+}$ & 15 & 1.02 & $0.70-1.50^{\#}$ & 15 & 0.74 & $0.43-1.25^{\#}$ & 14 & 1.02 & $0.58-1.79^{\#}$ \\
\hline \multicolumn{10}{|l|}{ Vanadium } \\
\hline Lag0 & 17 & 0.93 & $0.80-1.09^{\#}$ & 17 & 0.91 & $0.81-1.01^{\S}$ & 16 & 1.01 & $0.88-1.17^{\#}$ \\
\hline Lag1 & 17 & 0.93 & $0.83-1.05^{\#}$ & 17 & 0.97 & $0.87-1.08^{\S}$ & 16 & 1.00 & $0.90-1.12^{\#}$ \\
\hline Lag2 & 17 & 0.95 & $0.87-1.03^{\S}$ & 17 & 0.92 & $0.74-1.13^{\#}$ & 16 & 1.04 & $0.95-1.13^{\S}$ \\
\hline 7-day mean ${ }^{+}$ & 15 & 0.85 & $0.61-1.18^{\#}$ & 15 & 0.45 & $0.22-0.91 \#$ & 14 & 1.20 & $0.73-1.96^{\#}$ \\
\hline \multicolumn{10}{|l|}{ Sodium } \\
\hline Lag0 & 17 & 1.00 & $0.94-1.06^{\#}$ & 17 & 1.07 & $0.99-1.14^{\#}$ & 16 & 0.99 & $0.96-1.03^{\S}$ \\
\hline Lag1 & 17 & 1.01 & $0.98-1.04^{\S}$ & 17 & 0.99 & $0.92-1.06^{\#}$ & 16 & 0.99 & $0.94-1.00^{\S}$ \\
\hline Lag2 & 17 & 1.00 & $0.96-1.03^{\S}$ & 17 & 0.99 & $0.92-1.08^{\#}$ & 16 & 0.98 & $0.95-1.03^{\S}$ \\
\hline 7-day mean ${ }^{+}$ & 15 & 1.19 & $0.99-1.43^{\#}$ & 15 & 1.11 & $0.92-1.33^{\#}$ & 14 & 0.87 & $0.70-1.07^{\#}$ \\
\hline \multicolumn{10}{|l|}{ Lead } \\
\hline Lag0 & 17 & 1.01 & $0.94-1.08^{\#}$ & 17 & 0.99 & $0.95-1.03^{\S}$ & 16 & 1.01 & $0.97-1.05^{\S}$ \\
\hline Lag1 & 17 & 1.03 & $0.95-1.12^{\#}$ & 17 & 1.01 & $0.97-1.06^{\S}$ & 16 & 1.00 & $0.96-1.03^{\S}$ \\
\hline Lag2 & 17 & 1.01 & $0.98-1.04^{\S}$ & 17 & 0.97 & $0.88-1.06^{\#}$ & 16 & 0.99 & $0.92-1.06^{\#}$ \\
\hline 7-day mean ${ }^{+}$ & 15 & 1.04 & $0.89-1.22^{\#}$ & 15 & 0.95 & $0.67-1.36^{\#}$ & 14 & 0.89 & $0.70-1.12^{\#}$ \\
\hline \multicolumn{10}{|l|}{ Silicon } \\
\hline Lag0 & 17 & 1.05 & $1.00-1.10^{\#}$ & 17 & 1.00 & $0.94-1.06^{\S}$ & 16 & 1.00 & $0.95-1.05^{\#}$ \\
\hline Lag1 & 17 & 1.09 & $1.03-1.15^{\#}$ & 17 & 1.04 & $0.98-1.11^{\#}$ & 16 & 0.98 & $0.95-1.02^{\S}$ \\
\hline Lag2 & 17 & 1.05 & $0.99-1.11^{\#}$ & 17 & 1.01 & $0.93-1.10^{\#}$ & 16 & 1.01 & $0.97-1.04^{\S}$ \\
\hline 7-day mean ${ }^{+}$ & 15 & 1.18 & $1.02-1.37^{\#}$ & 15 & 0.87 & $0.71-1.05^{\#}$ & 14 & 0.87 & $0.79-0.96^{\S}$ \\
\hline \multicolumn{10}{|l|}{ PM10 } \\
\hline Lag0 & 17 & 1.00 & $0.94-1.07^{\S}$ & 17 & 1.00 & $0.87-1.15^{\#}$ & 16 & 0.99 & $0.92-1.08^{\S}$ \\
\hline Lag1 & 17 & 1.12 & $1.01-1.23_{s}^{\#}$ & 17 & 0.99 & $0.87-1.12^{\#}$ & 16 & 0.98 & $0.90-1.06_{\S}^{\S}$ \\
\hline Lag2 & 17 & 1.00 & $0.94-1.07^{\S}$ & 17 & 0.89 & $0.79-1.01^{\#}$ & 16 & 0.92 & $0.85-1.00^{\S}$ \\
\hline 7-day mean ${ }^{+}$ & 15 & 1.03 & $0.79-1.36^{\#}$ & 15 & 0.89 & $0.56-1.44^{\#}$ & 14 & 0.82 & $0.59-1.14^{\#}$ \\
\hline
\end{tabular}

*: increase of $1,000 \mathrm{ng} \cdot \mathrm{m}^{-3}$ (iron, sodium, silicon), $300 \mathrm{ng} \cdot \mathrm{m}^{-3}$ (zinc), $100 \mathrm{ng} \cdot \mathrm{m}^{-3}$ (lead), and $20 \mathrm{ng} \cdot \mathrm{m}^{-3}$ (vanadium), $10 \mathrm{ng} \cdot \mathrm{m}^{-3}$ (nickel) and $100 \mu \mathrm{g} \cdot \mathrm{m}^{-3}$ (particles with a $50 \%$ cut-off aerodynamic diameter of $10 \mu \mathrm{m}$ (PM10)); ${ }^{\ddagger}$ : panel-specific; ${ }^{\S}$ : fixed effects model; ${ }^{\sharp !}$ : random effects model. Lag0: current day; lag1: previous day; lag2: day before previous day; 7-day mean: mean of lag0-6 days.

this study was performed in the vicinity of a steel factory. These factors might explain the larger effect-estimates of iron on phlegm prevalence in the PEACE study compared to those of the Dutch study for the same increase in concentration, besides the differences in populations and health end points.

Phlegm prevalence was related to the concentration of silicon and iron, which are elements with a predominantly crustal origin and mainly form the coarse fraction of PM10. Elements which have industrial, combustion or traffic exhaust sources such as nickel, zinc, vanadium and lead and which mainly form the smaller fraction of PM10 were neither related to PEF nor to prevalence of respiratory symptoms and bronchodilator use. A study in the Netherlands [15] showed that $58 \%$ of the total silicon content in PM10 measured at a background site was extracted using a dilute acid extraction step. For iron, this was $81 \%$. In addition, the median soluble concentrations of silicon and iron were higher in PM10 than in particles with a 50\% cutoff aerodynamic diameter of $2.5 \mu \mathrm{m}$ (PM2.5) namely 165 and $9 \mathrm{ng} \cdot \mathrm{m}^{-3}$ respectively (silicon) and 351 and $86 \mathrm{ng} \cdot \mathrm{m}^{-3}$ respectively (iron). These figures show that, in that study, soluble silicon and iron predominantly originated in the coarse fraction. This could not be verified in the PEACE study as PM2.5 mass concentration was not measured.

Iron and other transition metals have been mentioned as elements which might be responsible for the association between PM10 and respiratory health [2], which is not the case for silicon. Silicates often have iron complexed on to their surface [25], which might be an explanation for the association between silicon and phlegm prevalence in this study. Neither iron nor silicon showed clear associations 


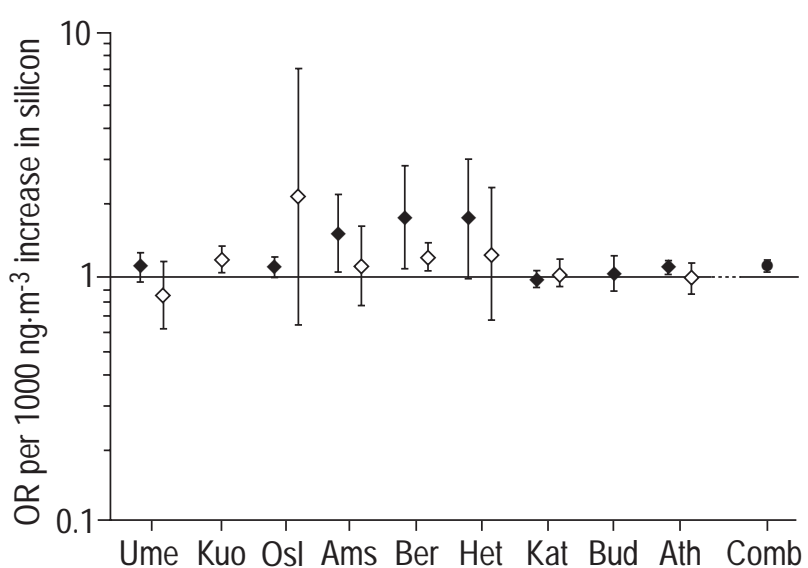

Fig. 1. - Individual panel and combined effect-estimates of silicon concentrations of previous day (lag1) on phlegm prevalence. $\bullet$ : urban; $\diamond$ : suburban; 0 : combined effect-estimate (Comb). The vertical bars represent 95\% confidence intervals. OR: odds ratio; Ume: Umeå; Kuo: Kuopio; Osl: Oslo; Ams: Amsterdam; Ber: Berlin; Het: Hettstedt; Kat: Katowice; Bud: Budapest; Ath: Athens.

with phlegm prevalence in a two-pollutant model with both iron and silicon concentrations as exposure variables in the same statistical model.

In conclusion, the composition of particulate matter differs between urban and suburban locations even when the mass concentration of particles with a $50 \%$ cut-off aerodynamic diameter of $10 \mu \mathrm{m}$ differs only to a limited extent. Daily iron and silicon concentrations were related to daily phlegm prevalence. Daily levels of other elements were not related to peak expiratory flow or daily prevalence of respiratory symptoms and bronchodilator use.

\section{References}

1. Dockery DW, Pope CA III. Acute respiratory effects of particulate air pollution. Annu Rev Public Health 1994; 15: $107-132$.

2. Seaton A, MacNee W, Donaldson K, Godden D. Particulate air pollution and acute health effects. Lancet 1995; 345: 176-178.

3. Smith KR, Aust AE. Mobilization of iron from urban particulates leads to generation of reactive oxygen species in vitro and induction of ferritin synthesis in human lung epithelial cells. Chem Res Toxicol 1997; 10: 828-834.

4. Ghio AJ, Hatch GE. Lavage phospholipid concentration after silica instillation in the rat is associated with complexed $\left[\mathrm{Fe}^{3+}\right]$ on the dust surface. Am J Respir Cell Mol Biol 1993; 8: 403-407.

5. Donaldson K, Brown DM, Mitchell C, et al. Free radical activity of PM10: iron mediated generation of hydroxyl radicals. Environ Health Perspect 1997; 105 (Suppl. 5): $1285-1289$.

6. Costa DL, Dreher KL. Bioavailable transition metals in particulate matter mediate cardiopulmonary injury in healthy and compromised animal models. Environ Health Perspect 1997; 105 (Suppl. 5): 1053-1060.

7. Dreher KL, Jaskot RH, Lehmann JR, et al. Soluble transition metals mediate residual oil fly ash induced acute lung injury. J Toxicol Environ Health 1997; 50: 285-305.

8. Ghio AJ, Stonehuerner J, Pritchard RJ, et al. Humic-like substances in air pollution particulates correlate with con- centrations of transition metals and oxidant generation. Inh Toxicol 1996; 8: 479-494.

9. Costa DL, Lehmann JR, Winsett D, McGee J, Ghio A. Pulmonary toxicity of Utah valley PM: are empirical indices of adverse health effects coherent with the epidemiology? Am J Respir Crit Care Med 1998; 152: A880.

10. Dusseldorp A, Kruize H, Brunekreef B, Hofschreuder P, de Meer G, van Oudvorst AB. Associations of PM10 and airborne iron with respiratory health of adults living near a steel factory. Am J Respir Crit Care Med 1995; 152: 1932-1939.

11. Hoek G, Schwartz JD, Groot B, Eilers P. Effects of ambient particulate matter and ozone on daily mortality in Rotterdam, the Netherlands. Arch Environ Health 1997; 52: 455-463.

12. Roemer W, Hoek G, Brunekreef B, et al. Effect of shortterm changes in urban air pollution on the respiratory health of children with chronic respiratory symptoms - the PEACE project: introduction. Eur Respir Rev 1998; 8: 52, 4-11.

13. Roemer W, Hoek G, Brunekreef B, Haluszka J, Kalandidi A, Pekkanen J, for the PEACE project. Daily variations in air pollution and respiratory health in a multicentre study: the PEACE project. Eur Respir J 1998; 12: 1354-1361.

14. Hoek G, Forsberg B, Borowska M, et al. Wintertime PM10 and black smoke concentrations across Europe: results from the PEACE study. Atmos Environ 1997; 31: 3609-3622.

15. Janssen NAH, van Manson DFM, van der Jagt K, Harssema $\mathrm{H}$, Hoek G. Mass concentration and elemental composition of airborne particulate matter at street and background locations. Atmos Environ 1997; 31: 1185-1193.

16. Reponen A, Ruuskanen J, Mirme A, et al. Comparison of five methods for measuring particulate matter concentrations in cold winter climate. Atmos Environ 1996; 30: 3873-3879.

17. Pope CA III, Dockery DW, Spengler JD, Raizenne ME. Respiratory health and PM10 pollution: a daily time series analysis. Am Rev Respir Dis 1991; 144: 668-674.

18. Pope CA III, Dockery DW. Acute health effects of PM10 pollution on symptomatic and asymptomatic children. $\mathrm{Am}$ Rev Respir Dis 1992; 145: 1123-1128.

19. Kleinbaum DG, Kupper LL, Muller KE. Applied Regression Analysis and other Multivariate Methods. Belpp. 200-201.

20. DerSimonian R, Laird N. Meta-analysis in clinical trials. Control Clin Trials 1986; 7: 177-188.

21. Roemer W, Hoek G, Brunekreef B. Effect of ambient winter air pollution on respiratory health of children with chronic respiratory symptoms. Am Rev Respir Dis 1993; 147: 118-124.

22. Lee DS, Garland JA, Fox AA. Atmospheric concentrations of trace elements in urban areas of the United Kingdom. Atmos Environ 1994; 28: 2691-2713.

23. Roemer W, Hoek G, Brunekreef B. Effect of ambient winter air pollution on respiratory health of children with chronic respiratory symptoms. Am Rev Respir Dis 1993; 147: $118-124$.

24. Peters A, Dockery DW, Heinrich J, Wichmann HE. Shortterm effects of particulate air pollution on respiratory morbidity in asthmatic children. Eur Respir J 1997; 10: 872-879.

25. Ghio AJ, Kennedy TP, Whorton AR, Crumbliss AL, Hatch GE, Hoidal JR. Role of surface complexed iron in oxidant generation and lung inflammation induced by silicates. Am J Physiol 1992; 7: L511-L518. 